\title{
Reinterpretation of Confucianism and Cultural Renaissance of Chinese Architecture
}

\author{
Xuejun Lin ${ }^{1,2, a}$, Guiwen $\mathrm{Li}^{1, \mathrm{~b}}$ and Ping Yin ${ }^{3, \mathrm{c}}$ \\ ${ }^{1}$ School of Architecture, Harbin Institute of Technology, Harbin, 150006, China \\ ${ }^{2}$ Shandong Vocational Institute of Urban Construction, Jinan, 250103, China \\ ${ }^{3}$ Luanwan Middle School, Pingyin County, Jinan, 250408, China \\ ajianzhukexue@163.com, 'liguiwen@hit.edu.cn, cyp13589045730@163.com
}

\begin{abstract}
Keywords: Architectural Renaissance, Confucianism, the Golden Mean of the Confucian School, Civil Rights, Self-Organizing.
\end{abstract}

\begin{abstract}
Problem-The constant culture and its tradition of Chinese architecture came to the edge of an exhaustive subversion, based on which the ecological recovery of Chinese architecture should be paid enough attention to as a kind of national strategic perspective. Crux-Under undue emphases put on politics, rigidly uniforms made as national plans habitually and economic construction taken as the national development center for a too long time, the forms, connotation and quality of Chinese buildings were alienated. Principle-In order to make for the value realization and the happiness of the livelihood, the maximum of respects for civil rights and the revival of traditional culture for national architecture, the Doctrine of the Mean should be advocated and restored. Method-By meanings of amending the "property law", the land reform can be developed and the holonomic ownership rights of real estate can follow behind; By meanings of decentralizing the jurisdiction of civilian construction, the self-organizing construction activity in the folk can be encouraged. Aims-Attempt to highlight the regional characteristics, interpret our national culture, inherit traditional techniques in architecture and establish a kind of collective harmony, where the exact collective unconscious nostalgia and memories can be shared among the civilians.
\end{abstract}

\section{Introduction}

Since the late of Qing Dynasty in China, the constant cultural tradition of Chinese architecture has been being alienated in the domestic trouble and foreign invasion, and it fell down into an imbalance of development together with the great leap forward of economy in the new China, where a kind of interrupt and extinction occurred. The architectural renaissance of Chinese architecture can not be approached until her modern history has been self-questioned deeeply, the ancient ones have been retrospect and the nutrients of Chinese traditional culture has been absorbed organically. The national independence and self-confidence of China should be picked up by meanings of encouraging civil rights, protecting the people's livelihood and demonstrating its national culture.

\section{Reexamination of Conficianism}

Confucianism was a master of Chinese ancient excellent thoughts and cultural heritage, a distinguished school of Chinese history, the mainstream culture and the mainstream ideology. It is an ethical systematology to coordinate relations, which managed to balance rights and wills, to coordinate developments so as to ensure them sustainable, to achieve intertemporal collective harmonies under series of dynamic maintenances and coordinations on levels, systems, orders and so on through every whole process.

It is the core of Confucianism to manufacture and maintain harmony, which does helps to correct the deviations in the developments of economy, science and technology; Confucianism is a seeding machine and an incubator, which can serve as a heuristic role in practical thoughts and implementation strategy of all walks of lives. The competitions, among industry products, enterprises 
as well as states and nations, are those among cultures in the final analysis. Neither technical nor functional products can approach the significance of value and the sublimation of Nirvana until they were endowed with cultural attaches.

\section{Evaluations of Confucianism}

In "Records of the Historian", Qian Sima, the Western Han Dynasty historian, said, "It could somehow be consistent with Confucius whatever was talked about 'Liuyi' from the princes down to the populace in China, which is why Confucius was known as the Holy Great teacher!"; It is a basic fact that the development and achievement of ancient Chinese was constucted under Confucianism[1]; Confucian context clues existed clearly in the development of Chinese ancient architecture, where deep influences were brought, and that is what Pro. Liangyong Wu called Confucius aesthetics characteristic[2]; The Declaration of the Paris Conference, held for Nobel Prize winners in January 1988, presented that humanbeings had to look back 2540 years so as to learn from Confucius[3].

\section{Interpretation about the Doctrine of the Mean}

"Before any emotions such as pleasure, anger, sorrow, joy and so on released, neutral remains; and harmony comes after their emits follow principles". Yong(庸) means permanent, frequent and execution. Confucian doctrine was scrupulously abide by in a kind of mid-road without losing the general balance and with things well done without an error instead, which was universally applicable wherever and which concerned about both the present and the future.

Mr. Pu Pang, a professor of China Academy of Social Sciences, thought the Doctrine of the Mean was more of a standpoint, perspective and method of Philosophy to the world than the development of a kind of ethics or the concept of metaphysics, in which moral truths were achieved from the moralities. He turned the common doctrine into a sublime named a theory of "One Divided into Three", and he thought it contained a unique Chinese characteristics of harmony, where the modern theory of contradiction, either this or that or "One Divides into Two", was removed . And thus, the new thoery showed the "opposite logic attribute the same" instead of "unity of opposites" while it kept the essence of the modern "negation of negation" contradictory unity theory. That is what the new doctrine means "holding both ends with harmony in both to create the third newborn thing so as to establish a harmonious whole".

\section{Extension of Confucianism}

It should be preferred learning more from both the history and real life experience rather than applying experimental theories to the social and cultural practice mechanically. It should be avoided to "crossing a river by means of blindly feeling stones recklessly", and the phenomenons of sloganizing reforms should be minimized.

According to the principle of Confucian doctrine of the mean, it is necessary to deal with the relationships between the following:

Inheritance and development

A sery of sustainable plannings should be formulated and the suitable evaluation system should be established in order to build the relevance of dynamic equilibrium among the traditional, modern and future. Make it impossible to combine national and regional characteristics, while the era temperaments of culture and technology are endowed in the meantime.

Evolution and Revolution

Give a correct understanding to the relationship between qualitative changes and quantitative ones. More attention ought to be paid to gradual changes, self-discipline, refine on qualities. Try to accumulate richly and break forth vastly so that the organic association in the diachronic developments will not be interrupted easily, where revolution comes out of evolution gradually and naturally. 
Assimilation and Dissimilation

Such thoughts of Zhidong Zhang, one of the pioneers in the Qing Dynasty Westernization Movement, are needed to be re examined as "Lead the past to serve the present and carry foreign things to serve China", "Learn from the national as the body, and implement the western for uses" etc. It is necessary to ensure Chinese cultural gene line can be kept pure and be determined enough, which can be called a sustainable development of culture.

\section{A Brief Historical Relation between Confucianism and Chinese Culture}

According to the Chinese official history, the history of China can be divided into the following such stages as primitive society $\left(1^{\text {st }}\right.$ period $)$, slave $\operatorname{society}\left(2^{\text {nd }}\right)$, feudal $\operatorname{society}\left(3^{\text {rd }}\right)$ and $\operatorname{socialist}$ $\operatorname{society}\left(4^{\mathrm{th}}\right)$.

The $1^{\text {st }}$ period has another name of Primitive Communism. But in "Records of the Historian", Qian Sima presented obvious characteristics of feudal society in Chronicles of the Five Emperors First, when the caste system and vassalage were already very strict. That is to say, its political features of a feudal society formed and existed objectively.

The $2^{\text {nd }}$ one generally refers to the three dynasties, Xia, Shang and Zhou, which was the growth and maturity period of Chinese culture. Scientific and cultural knowledge used to be the social benefits of the upper-class, where cultures and arts were created in a top-down order.

Born in the late Zhou Dynasty's, Confucius generated the great Confucian system of his from the above three generations, whose education practice of no social distinctions in teaching spread education to the folk. From then on, the two lines, top-down and bottom-up, were kep abreast with each other in creations of cultures and arts, and the latter one played more importantly, which kept the same in the $3^{\text {rd }}$ period from the Qin Dynasty to the Qing Dynasty.

Since 1840, the end of the Qing Dynasty, the modern times of China began. The invasion of the Eight Power Allied forces compelled the Chinese government to be opened, which promoted the rising up of the Westernization Movement. External forces drove the development of science and technology forward into an one-sided comprehensive Westernization in China, whose influence has been kept seriouly up to now. On the other hand, New Culture Movement occurred in China in May 4,1919 , where strong political purposes were carried forward and the traditional thousands of years long culture of China was overturned thoroughly, espectialy Confucianism was criticized as the main target. As a result, although the "Chinese immanent form" movement in architecture-designings was raise in construction industry in 1920 s, the recession fell down neither in the traditional culture nor in the architecture.

In the $4^{\text {th }}$ period, a Russianization movement and the people's Commune Movement occurred in the 1950's, which resulted that all the land was nationalized, architectural shaping was Russianized and the top-down line built in the feudal society was interrupted.

During 1966 to 1976, the tumultuous Cultural Revolution destroyed Confucianism completely and a catastrophic destruction fell down upon traditional architecture.

In 1980s-1990s, together with the rural and economic reform, the western modernism impacted China. Scientific Technology became a new religion and modernistic architecture blossomed all over China. A hollowing out of architectural culture especially of Chinese traditional architectural culture took place, where the DNA of Chinese traditional architecture mutated as a kind of cultural virus .

During the early ten years in 21 st century, real estate became a pillar industry of Chinese economy development, a tool and lever of profits, the elegant and quiet mode of traditional development was marginalized.

Since 2010, real estate went into an adjustment period. With series of policies proposed and implemented, for example, adjustment of industrial structure, emphasis on the development of cultural industry, ecological civilization construction, harmonious socialist society construction and paying more attention to inclusive development, the return to the traditional culture spirit. The 
cultural renaissance of national culture and national construction came to meet with a long time expectation.

In a word, the rise of Confucianism is conducive to the healthy development of Chinese architecture.

\section{Confucian thoughts for Chinese cultural renaissance}

Principle: both, friendly, balance, sustainability and harmony.

\section{Amendments to Real Right Law of the People's Republic of China}

Real Right Law of the People's Republic of China was enacted in March 16, 2007. "To meet the needs of public interests, in accordance with the authority and procedures prescribed by law, the expropriation of collectively owned land, units's or individual housing and other real estate"(Article 42, Chapter 4 General Provisions, Part 2 Ownership) was the negation of "Property rights are protected by law, any unit and individual shall not be violated" (Article 4, Unit 1 Basic Principles, Part 1 General Provisions).

It is necessary to do a deep amendment upon the Real Right Law of the People's Republic of China in order to turn the real right property of the citizens into a full ownership, where the rights of the civil individuasl situate above both the collective rights and the state power. Ensure that the true spirit of contract can be defended without any compromise by laws, where all the property owers can enjoy the law-protected peace of mind and can do any investments and constructions freely, willingly and sustainably. Furtherly, the encouragements from the state and the supports from national laws can stimulate the civils, their families and their clans to devote themselves, their wealth and their wisdom to the establishment on private propert to meet with the spirit of Maslow's theory of needs.

States are more concerned with politics and cultures are related to their nations more closely, which presents that it is benefit to the national profits to release powers and rights to the people, and in a common cause, culture is bound together with the people and their nation intimately.

\section{Adjustment to the National Culture Policy}

In the development policies of national culture, including the development of architectural culture, Law of P.R.C. on the Autonomy of Minority Nationality Region was enacted in October 1, 1984, which presented the full respects and protections from the state upon the minority rights to manage their internal affairs. On the one hand, the minority nationality people can inherit and carry forward the excellent tradition of their national culture, social customs and freedom of religion believes, and on the other hand, based on Chinese ruling political consideration, the traditional cultures of the Han nationality were suppressed to some extent, which led to an embarrassing situation " Only the minority cultures belong to the world instead of the other's ".

Proposal: Political programs must manage to ensure that different nationalities can share equal rights and the same cultural developments. Enough legal and policy supports should be given to recover the cultural ecology of the Han nationality architecture in order to keep a balance among the architectural developments of 56 nationalities.

Here presents a macro "the doctrine of the mean" upon cultural developments of Chinese architecture.

\section{Introspection to the material, technology and energy conservation}

The selection of building materials should obey such a principle as suiting their local conditions and optimizing the use of resources. A kind of non renewable resource cannot be protected in theory (for example, mountains were overexploited severely because clay brick was disabled in China) while some others were led to an accelerated exhaustion. No difference should not be an interpreter of mandatory laws, and material recycling should be encouraged, which can be called a kind of micro technology of "The doctrine of the mean".

\section{Stimulation to the autonomy of design and construction}

The construction of self-organization from the folk have more nice virtues of traditional ethics, which is more conducive to group harmony and easier to improve the well-being neighborhood, and 
thus can revive the architectural art of traditional ethnic groups in contemporary China. The Confucian architectural idea of "harmony but not sameness" can only be established by the people instead of the government for others.

\section{Transmission to deny selves and return to propriety}

Chinese traditional architecture implied Confucian ethics both in material modeling similarities and spiritual modeling ones, which was achieved by denying individual selves to return to collective proprieties. It was an inheritance of material genes for individual buildings to imitate and repeat the symbols of its surrounding ones(Fig. 1), and it was an inheritance of spiritual genes to communicate with the collective surroundings friendly and politely outside and to restrain family members with constraints inside(Fig. 2), which is quite different from these at present.

Proposal: By means of giving legal status to urban designing and regulatory planing, prohibit constant strange, morose, confused and magical heroics in architectural designing and planing and establish traditional functions of ethics inside buildings.

\section{Conclusion}

The history of Chinese cultural development is the one of the ups and downs of Confucianism, the development of science, technology and economy needs ethical constraints, and the cultural renaissance of Chinese architecture is determined by how and what it absorbs the ideas and strategies from Confucianism.

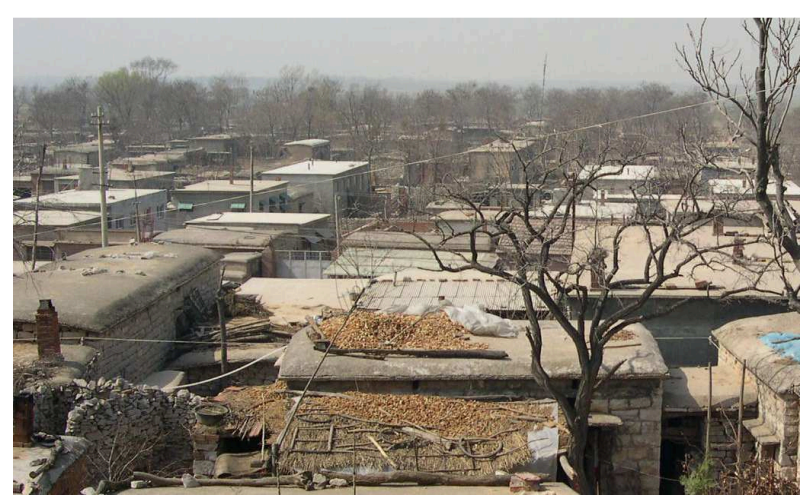

Fig. 1 Collective similarity

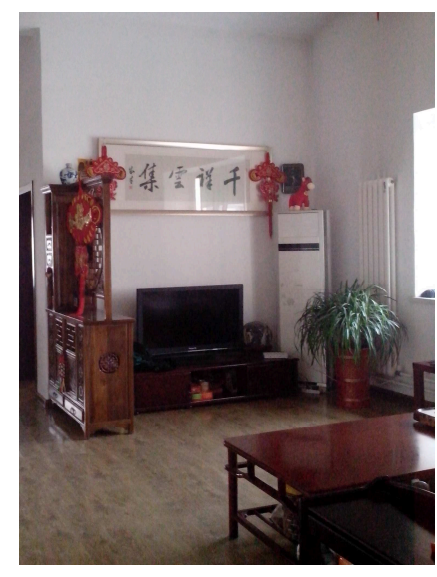

Fig. 2 Modern

(TV Centered)

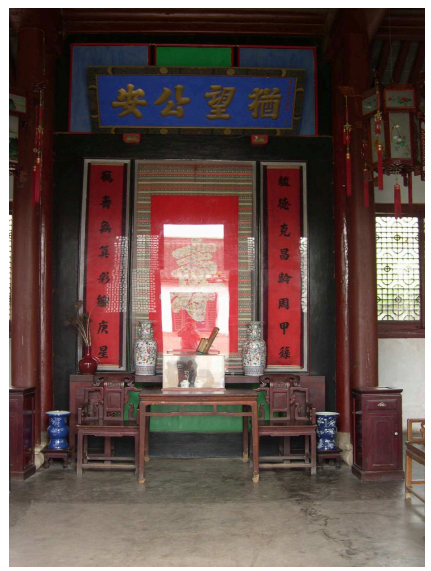

Historical

(Rlders Centered)

\section{References}

[1] L. Aiguo: Confucianism and Science in the Song Dynasty. In: China Science and Technology Press, Peking, (2007).4, pp. 7

[2] W. Liangyong: Qufu Confucius Research Institute, Tsinghua University press, Peking, (2011).4, pp. $9-10$

[3] Z. Jihui: New development of Confucianism research in twenty-first Century. In: Social Sciences Academic Press, (2004).6, p. 1 